Gut, 1972, 13, 755-758

\title{
The stimulant effect of drugs on indocyanine green clearance by the liver
}

\author{
V. MELIKIAN ${ }^{1}$, J. D. EDDY ${ }^{2}$, AND A. PATON
}

From Dudley Road Hospital, Birmingham

SUMMARY The rate of removal of a standard dose of $25 \mathrm{mg}$ indocyanine green was studied in 67 patients at the bedside using dichromatic ear densitometry. The determination of the percentage disappearance rate per minute and the half life of the dye permitted separation of patients into three groups: those with normal liver function, those with liver damage, and a group taking opiates (9), anticonvulsants(8), phenylbutazone (2), haloperidol (1), and nitrofurantoin (1). The last group showed enhanced clearance of indocyanine green from the circulation.

The dye indocyanine green has been shown to be an excellent agent for studying hepatic function (Fox, Brooker, Heseltine, Essex, and Wood, 1957; Wheeler, Cranston, and Meltzer, 1958; Rapaport, Ketterer, and Wiegand, 1959; Cherrick, Stein, Leevy, and Davidson, 1960; Hunton, Bollman, and Hoffman, 1960; Caesar, Shaldon, Chiandussi, Guevara, and Sherlock, 1961). It is rapidly bound to plasma albumin after intravenous injection (Cherrick et al, 1960), undergoes no enterohepatic or extrahepatic circulation, and is taken up exclusively by the liver (Wheeler et al, 1958; Rapaport et al, 1959; Cherrick et al, 1960; Hunton et al, 1960). It is secreted almost entirely into the bile but not in conjugated form (Wheeler et al, 1958; Rapaport et al, 1959; Cherrick et al, 1960). Plasma measurements are unaffected by the level of serum bilirubin. This and its lack of toxicity make indocyanine green valuable for serial studies of liver function both in health and disease.

The use of a dichromatic ear piece densitometer (Reed and Wood, 1964) for detecting plasma indocyanine green obviates the need for biochemical estimations (Howard, Senyszyn, and Leevy, 1965; Leevy, Smith, Longueville, Paumgartner, and Howard, 1967) and results obtained for percentage disappearance rate per minute and half life $(t / 2)$ show good correlation with those determined by plasma dye measurements (Howard et al, 1965;

'Present address: The General Hospital, Birmingham B4 6NH

'Present address: Good Hope General Hospital, Sutton Coldfield, Warwicks

Received for publication 6 September 1972.
Leevy et al, 1967; Andersen and Kuchiba, 1970). Since the test is carried out at the patient's bedside, it provides a rapid assessment of liver function. While employing this method in drug addicts we were struck by their rapid removal of indocyanine green, and we have therefore studied the effect of drugs on the test. The results are compared with those obtained in normal subjects and in patients with liver damage.

\section{Patients}

Sixty-seven patients (40 male, 27 female) between the ages of 21 and 85 were studied, three of them on two occasions each.

\section{GROUP I}

These 11 patients had normal liver function as judged by clinical and biochemical evidence.

\section{GROUP II}

Of 38 patients with liver dysfunction, 27 had biochemical and/or histological evidence of hepatitis or cirrhosis. These have been labelled 'liver disease'. The remaining 11 consisted of patients with lymphomas, liver metastases, and one taking an oral contraceptive, all of whom had abnormal liver function tests. This subgroup has been labelled 'liver involvement'. None were on enzyme-inducing drugs (Levi, Sherlock, and Walker, 1968).

GROUP III

These were 12 patients receiving anticonvulsants (8), phenylbutazone (2), haloperidol (1), nitrofurantoin 
(1), and nine addicted to one or more of heroin, methadone, morphine, pethidine, or poppy heads. All had normal liver function, with the exception of two addicts, who were subsequently found to have liver damage on biopsy.

\section{Methods}

Indocyanine green clearance was measured by a Waters dichromatic ear densitometer which had a compensatory photoelectric cell to correct for variations in blood volume, haematocrit, oxygen saturation, and $\mathrm{pCO}_{2}$ and a detection photocell to register levels of the dye in the circulation. With the patient recumbent and the ear piece attached to the pinna, indocyanine green was injected into an antecubital vein as a bolus, and the densitometer readings were recorded continuously on a chart recorder.

A standard dose of $25 \mathrm{mg}$ indocyanine green was used in each patient. In three normal subjects repeated clearance tests were carried out using doses of $25 \mathrm{mg}$ and $0.5 \mathrm{mg} / \mathrm{kg}$ body weight and the results agreed to within $5 \%$ provided the studies were not carried out within an hour of each other. Only the results of the $25 \mathrm{mg}$ clearance tests were included in the overall analysis.

Readings were taken at 20 -second intervals from the dye decay curve and the method of least squares was used to establish the regression line between the logarithm of the densitometer reading and time. The half life $(t / 2)$ of the dye was calculated, and the percentage disappearance rate (PDR) per minute was obtained from the formula (Leevy et al, 1967):

$$
P D R=\frac{0.693}{t / 2} \times 100
$$

\section{Results}

Table I summarizes the mean percentage disappearance rate per minute and half life of indocyanine green in the three groups of subjects studied, and representative clearances plotted on semilogarithmic paper are shown in Figure 1.

\begin{tabular}{llcc}
\hline No. & Group & $\begin{array}{c}\text { Percentage Disappearance } \\
\text { Rate per Minute }\end{array}$ & $\begin{array}{c}\text { Half Life } \\
\text { in Minutes }\end{array}$ \\
\hline 11 & Normal & $50.6 \pm 1.98$ & $1.3 \pm 0.05$ \\
38 & Liver dysfunction & $24.8 \pm 1.76$ & $3.9 \pm 0.53$ \\
21 & Drugs & $115.8 \pm 8.04$ & $0.65 \pm 0.04$ \\
\hline
\end{tabular}

Table I Mean percentage disappearance rate per minute and half life of indocyanine green measured by dichromatic ear densitometry (70 observations in 67 subjects $)^{1}$

${ }^{1}$ Figures indicate mean \pm standard error

The mean percentage disappearance rate was $50 \cdot 6$ per minute in subjects without liver disease, while patients with abnormal liver function had a mean of 24.8 per minute. The mean percentage disappearance rate for the patients who were taking drugs but had normal liver function was $115 \cdot 8$ per minute.

Similarly, the mean $t / 2$ for the three groups was $1.3,3.9$, and 0.65 minutes respectively. There thus appears to be a definite range for each group with some overlap both for percentage disappearance rate (Fig. 2) and $\mathrm{t} / 2$, despite the fact that a constant dose of dye was used.

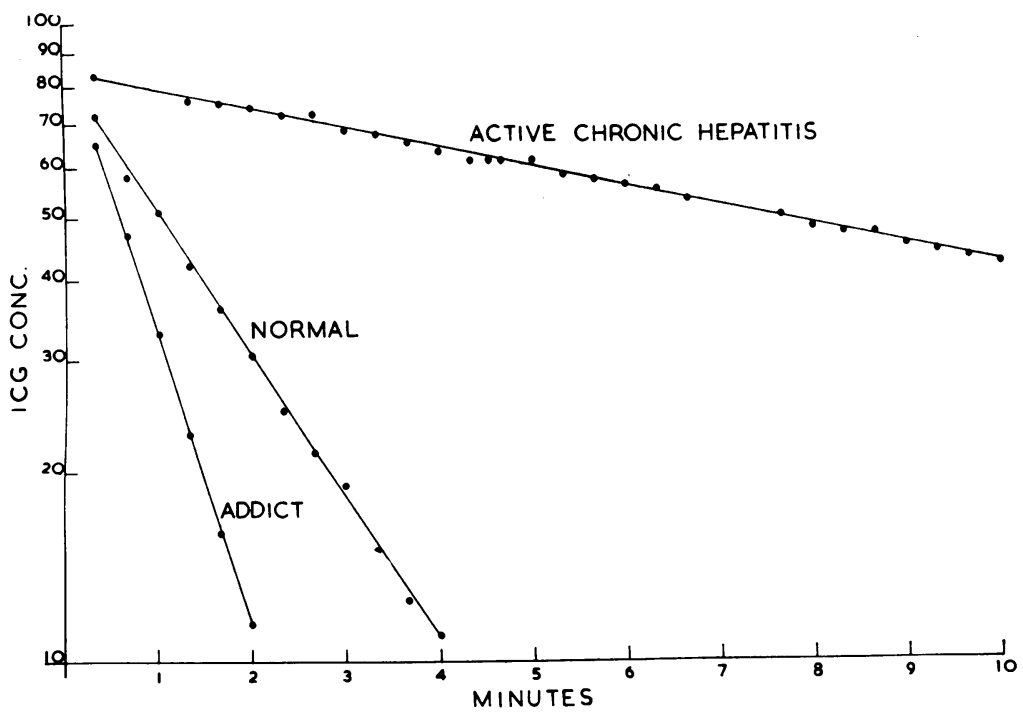

Fig. 1 Examples of indocyanine green clearance in each of the three groups of patients. ICG Conc. = indocyanine green concentrations as recorded by densitometer. 


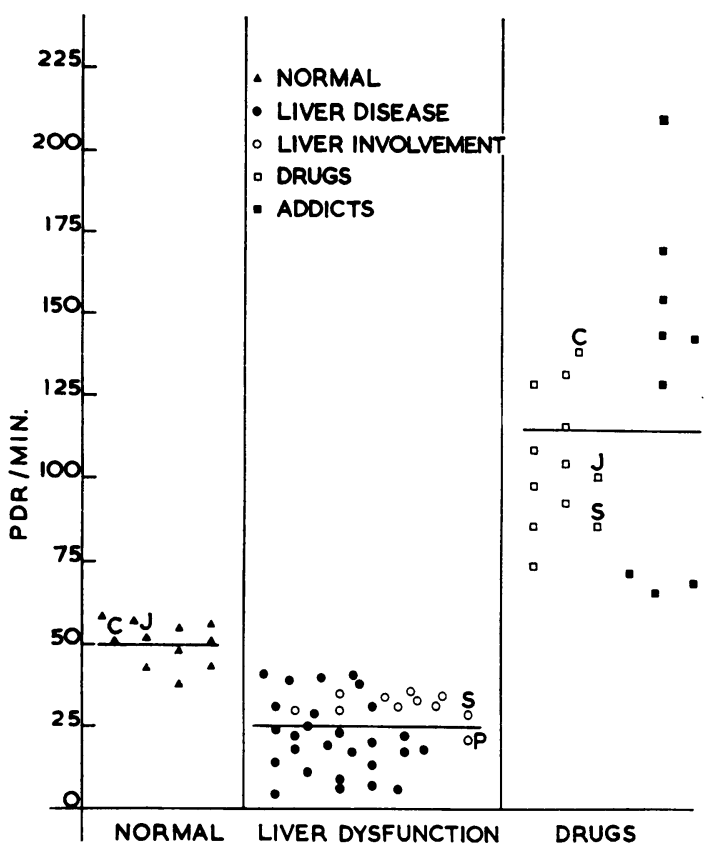

Fig. 2 Percentage disappearance rate per minute $(P D R /$ min) of indocyanine green in the three groups of patients studied. Bar indicates mean value.

C Before $\square_{\text {S }}$ after phenylbutazone
S Before $\square_{\text {J }}$ after phenylbutazone
J Before $\square$ after phenobarbitone

$\bigcirc \mathbf{P}$ Patient receiving probenecid

In general, patients with 'liver disease' had a rate below the mean for group II, while patients with 'liver involvement' tended to have higher rates (Fig. 2). One patient, who had a carcinoma of the pancreas and was included in the 'liver involvement' group, was taking probenecid for gout, a drug which has been shown to decrease plasma indocyanine green clearance in the dog (Vogin, Scott, Boyd, Bear, and Mattis, 1966). Patient S, taking an oral contraceptive, was later re-tested after treatment with phenylbutazone for a superficial thrombophlebitis (see below).

All patients who were either drug addicts or were receiving drugs for therapeutic purposes showed increased plasma indocyanine green clearance (Fig. 2). The patient with the highest percentage disappearance rate ( 210 per minute) was taking heroin and opium and had a normal liver biopsy, while the two lowest rates (67 and 69 per minute) occurred in the two addicts with liver damage. In spite of this, their plasma indocyanine green clearance was above the range for normal subjects.

Patients on anticonvulsants were receiving either phenobarbitone, a combination of phenobarbitone and phenytoin, or a mixture of phenobarbitone, primidone, and sulthiame. All showed an increased percentage disappearance rate as did the two patients who were receiving haloperidol and nitrofurantoin respectively. Patients $C$ and $S$ (Fig. 2) were treated with phenylbutazone for superficial thrombophlebitis. Indocyanine green clearance was measured before and after two weeks' therapy and a marked increase in percentage disappearance rate per minute was demonstrated. A similar result was obtained in patient $J$, who received phenobarbitone during treatment for a gastric ulcer.

\section{Discussion}

Dichromatic ear densitometry with indocyanine green has been used by many workers (Howard et al, 1965; Leevy et al, 1967; Andersen and Kuchiba, 1970) as a test of liver function, since Fox et al (1957) reported that the dye was removed from the circulation at a constant rate and Reed and Wood (1964) showed that its disappearance could be recorded by a photoelectric cell.

A constant dose $(25 \mathrm{mg})$ of indocyanine green was used in the present study. Several authors, however, have used a dose of $0.5 \mathrm{mg} / \mathrm{kg}$ body weight, while Leevy et al (1967) have suggested that larger doses ( $5 \mathrm{mg} / \mathrm{kg}$ body weight) should be used in order to detect mild liver disease. Recently, Andersen and Kuchiba (1970) have shown that reliable and reproducible hepatic decay curves can be produced with doses as low as $0.25 \mathrm{mg} / \mathrm{kg}$ body weight. We were unable to find any significant difference in disappearance rate at two different dose levels in three individuals.

In our hands, the results of the test fell into three distinct categories, differentiating normal subjects from patients with liver dysfunction and those taking drugs. Using a constant dose $(25 \mathrm{mg})$, which represented a mean figure of $0.4 \mathrm{mg} / \mathrm{kg}$ body weight (range $0.27-0.64 \mathrm{mg} / \mathrm{kg}$ body weight; $\mathrm{SD} \pm 0.08$ ), our normal range for percentage disappearance rate was 38-58 per minute, figures which are greater than the 18-25 per minute obtained by other authors (Rapaport et al, 1959; Cherrick et al, 1960; Hunton et al, 1960; Cooke, Harrison, and Skyring, 1963; Leevy et al, 1967). Nevertheless, it was still possible to assign individuals according to the percentage disappearance rate (and $t / 2$ ) into one of three groups, which corresponded with the clinical, biochemical, and histological findings.

Patients with cirrhosis or hepatitis, as was to be 
expected, had a much reduced percentage disappearance rate and increased $t / 2$. Those with slight to moderate liver damage had values which merged with the range found in normal subjects. This agrees with the findings of Hunton et al (1960) and Leevy et al (1967).

Indocyanine green is rapidly removed from the plasma, stored in the liver, and secreted slowly into bile (Wheeler et al, 1958; Rapaport et al, 1959; Cherrick et al, 1960; Hunton et al, 1960). The most striking finding in the present study was the above normal clearance of the dye by patients receiving drugs and by addicts, and presumably this could be due to increased uptake by the liver cell, enhanced binding by specific hepatic carrier proteins, or more rapid excretion into bile. Since some of the processes are enzyme-mediated, it would be tempting to postulate that rapid clearance is a reflection of enzyme induction. However, this phenomenon usually refers to drug-metabolizing microsomal enzymes, and, since indocyanine green is not conjugated it seems unlikely that enzyme induction is responsible. Alternative possibilities are increased synthesis of hepatic carrier proteins or increased bile flow, both of which have been demonstrated in animal experiments following drug administration (Reyes, Levi, Gatmaitan, and Arias, 1971; Conklin and Wagner 1971). There is as yet no information that these mechanisms are stimulated in man by drugs and the present findings cannot be explained. There is some evidence from patient $S$ and the two addicts with liver damage that drugs are still capable of enhancing indocyanine green clearance in the diseased liver. If this implies improved hepatic function indocyanine green clearance could be used as a simple and safe procedure for repeated assessment.

We wish to thank Dr S. P. Singh for the use of the densitometer and Dr K. Dixon for invaluable help with the mathematical interpretation of the dye decay curves. Dr J. Owens kindly allowed us to study addicts under his care.

\section{References}

Andersen, M. N., and Kuchiba, K. (1970). Measurement of acute changes in liver function and blood flow. Arch. Surg., 100, 541-545.

Caesar, J., Shaldon, S., Chiandussi, L., Guevara, L., and Sherlock, S. (1961). The use of indocyanine green in the measurement of hepatic blood flow and as a test of hepatic function. Clin. Sci., 21, 43-57.

Cherrick, G. R., Stein, S. W., Leevy, C. M., and Davidson, C. S. (1960). Indocyanine green: observations on its physical properties, plasma decay, and hepatic extraction. $J$. clin. Invest., 39, 592-600.

Conklin, J. D., and Wagner, D. L. (1971). Excretion of nitrofurantoin in dog hepatic bile. Brit. J. Pharmacol., 43, 140-150.

Cooke, A. R., Harrison, D. D., and Skyring, A. P. (1963). Use of indocyanine green as a test of liver function. Amer. J. dig. Dis., 8, 244-250.

Fox, I. J., Brooker, L. G. S., Heseltine, D. W., Essex, H. E., and Wood, E. H. (1957). A tricarbocyanine dye for continuous recording of dilution curves in whole blood independent of variations in blood oxygen saturation. Proc. Mayo Clin., 32, 478-484.

Howard, M. M., Senyszyn, J., and Leevy, C. M. (1965). Use of dichromatic ear densitometry to evaluate kinetics of indocyanine green removal in liver disease. Gastroenterology, 48, 501-502.

Hunton, D. B., Bollman, J. L., and Hoffman, H. N. (1960). Studies of hepatic function with indocyanine green. Gastroenterology, 39, 713-724.

Leevy, C. M., Smith, F., Longueville, J., Paumgartner, G., and Howard, M. M. (1967). Indocyanine green clearance as a test for hepatic function. J. Amer. med. Ass., 200, 236-240.

Levi, A. J., Sherlock, S., and Walker, D. (1968). Phenylbutazone and isoniazid metabolism in patients with liver disease in relation to previous drug therapy. Lancet, 1, 1275-1279.

Rapaport, E., Ketterer, S. G., and Wiegand, B. D. (1959). Hepatic clearance of indocyanine green. Clin. Res., 7, 289-290.

Reed, J. H., Jr., and Wood, E. H. (1964). Use of dichromatic ear piece densitometry for determination of cardiac output. Biophysics Laboratory, Aerospace Medicine Research Laboratory, Aerospace Medicine Division, Airforce Systems Command, Wright-Patterson Airforce Base, Ohio (AMRL-TR64-134), December 1964, pp. 1-13.

Reyes, H., Levi, A. J., Gatmaitan, Z., and Arias, I. M. (1971). Studies of $\mathbf{Y}$ and $\mathrm{Z}$, two hepatic cytoplasmic organic anion-binding proteins: effect of drugs, chemicals, hormones, and cholestasis. J. clin. Invest., 50, 2242-2252.

Vogin, E. E., Scott, W., Boyd, J., Bear, W. T., and Mattis, P. A. (1966). Effect of probenecid on indocyanine green clearance. J. Pharmacol. exp. Ther., 152, 509-515.

Wheeler, H. O., Cranston, W. I., and Meltzer, J. I. (1958). Hepatic uptake and biliary excretion of indocyanine green in the dog. Proc. Soc. exp. Biol. (N.Y.), 99, 11-14. 